\title{
Effect of concentration on the physical properties of cashew juice
}

\author{
Patricia Moreira Azoubel ${ }^{a, *}$, Débora Cristina Cipriani ${ }^{b}$, Ânoar Abbas El-Aouar ${ }^{\text {b }}$, \\ Graziella Colato Antonio ${ }^{b}$, Fernanda Elizabeth Xidieh Murr ${ }^{b}$ \\ ${ }^{a}$ Embrapa Semi-Arid, BR 428, Km 152, P.O. Box 23, Petrolina, PE 56302-970, Brazil \\ b Department of Food Engineering, College of Food Engineering, State University of Campinas, P.O. Box 6121, Campinas, SP 13083-970, Brazil
}

Received 18 November 2003; accepted 4 April 2004

\begin{abstract}
Thermal conductivity, thermal diffusivity, density and viscosity of cashew juice were measured at $30{ }^{\circ} \mathrm{C}$ for soluble solids content ranging from 5.5 to $25^{\circ}$ Brix. Thermal conductivity and diffusivity were determined using a linear heat source probe. Both properties were found to decrease with the increase of soluble solids content, while density and viscosity increased. Empirical models were fitted to the experimental data for each property and the accuracy of those models was checked.
\end{abstract}

(c) 2004 Elsevier Ltd. All rights reserved.

Keywords: Cashew juice; Density; Thermal properties; Thermal diffusivity; Thermal conductivity; Viscosity

\section{Introduction}

Cashew juice is widely available on the Brazilian market. This juice, which is a complex mixture of vitamins, polyphenols, sugar, mineral salts, organic acids and amino acids, is an excellent source of vitamin $\mathrm{C}$, containing approximately six times more vitamin $\mathrm{C}$ than orange juice (da Silva, Collares, \& Finzer, 2000; Soares $\&$ Maia, 1970).

A knowledge of thermal properties is necessary for effective design of food processing equipment, such as heat exchangers and other equipment requiring pumping of the product (de Moura, Germer, Jardim, \& Sadahira, 1998).

Over the years both measured values of thermophysical properties of food as well as the mathematical models for their calculation have been published (Bhumbla, Singh, \& Singh, 1989; de Moura et al., 1998; Dickerson, 1968; Polley, Synder, \& Kotnour, 1980; Riedel, 1949). However, the majority of the available data for fruits are for sub-tropical ones. Little published information is available about the thermal properties of tropical fruit products like juices. 1744.

\footnotetext{
${ }^{*}$ Corresponding author. Tel.: +55-87-3862-1711; fax: +55-87-3862-

E-mail address: pazoubel@cpatsa.embrapa.br (P.M. Azoubel).
}

The objective of this work was to determine density, thermal conductivity, thermal diffusivity and the rheological behaviour of cashew juice as a function of soluble solids content and to compare the experimental data and the values obtained from the mathematical models found in the literature.

\section{Theory}

Several methods are available to measure physical properties of food. The line heat source probe can be employed for the determination of thermal conductivity and thermal diffusivity simultaneously (Choi \& Okos, 1983; Nix, Lowery, Vachen, \& Tanger, 1967). Advantages of this method are the short duration of the experiments, simplicity, speed and relatively small sample requirement (AbuDagga \& Kolbe, 1997; Tocci, Flores, \& Mascheroni, 1997).

The theory of this method is presented in detail by many researchers (Blackwell, 1954; Nix et al., 1967) and is based on the fact that the temperature rise at a point close to a line heat source, in a semi-infinite solid, subjected to a step change heat source, is a function of time, the thermal properties of the solid and the source strength (Choi \& Okos, 1983). The expression in which the thermal conductivity may be obtained is 
$k=\frac{Q \ln \left(t_{2}-t_{0}\right) /\left(t_{1}-t_{0}\right)}{4 \pi\left(T_{2}-T_{1}\right)}$,

where $k$ is the thermal conductivity of the sample $\left(\mathrm{W} \mathrm{m}^{-1} \mathrm{~K}^{-1}\right), Q$ is the heat source strength $\left(\mathrm{W} \mathrm{m}^{-1}\right), t_{1}$ and $t_{2}$ are the initial and final times (s), respectively, when $\ln (t)$ versus $T$ plot becomes linear and $T_{1}$ and $T_{2}$ are the temperature $(\mathrm{K})$ at times $t_{1}$ and $t_{2}$, respectively.

A time correction factor $\left(t_{0}\right)$ was introduced to correct the effect of finite heat diameter and finite heat resistance between the heat source and the sample (Van der Held \& Van Drunen, 1949).

The determination of thermal diffusivity using the line source technique is possible without information of density and specific heat by using the following expression (Choi \& Okos, 1983):

$T=\frac{Q}{2 \pi k} \int_{\beta}^{\alpha} \frac{\exp \left(-\beta^{2}\right)}{\beta} \mathrm{d} \beta$,

where $\beta$ is inversely proportional to $(\alpha)^{0.5}$ :

$\beta=\frac{r}{2 \sqrt{\alpha t}}$,

where $r$ is the distance from the heat line (m) and $\alpha$ is the thermal diffusivity $\left(\mathrm{m}^{2} \mathrm{~s}^{-1}\right)$.

Nix et al. (1967) give the following series expression for evaluation of the above integral:

$T=\frac{Q}{2 \pi k}\left[-\frac{C_{\mathrm{e}}}{2}-\ln \beta+\frac{\beta^{2}}{2 \times 1 !}-\frac{\beta^{4}}{4 \times 2 !}+\cdots\right]$,

where $C_{\mathrm{e}}$ is Euler constant (0.577).

Nix et al. (1967) found that the first 40 terms of the above equation need to be evaluated to insure convergence. However, for values of $0<\beta<0.16$, the residual error occurs if only the first two terms within the brackets are taken. That condition is easily attained if the probe and the point where temperature is measured are closely located and the time is larger (order of minutes; Urbicain \& Lozano, 1997).

\section{Material and methods}

\subsection{Materials}

Cashew juice at various soluble solids content (5.5-25 ${ }^{\circ}$ Brix) was made from a $9.6{ }^{\circ}$ Brix pulp obtained in a local market of Campinas, Brazil. The main characteristics of this pulp juice are summarized in Table 1.

The $5.5^{\circ}$ Brix juice was made by reconstituting the original pulp with distilled water. The concentration of cashew juice was carried out in a rotary evaporator, in which the evaporation chamber was rotating at a constant speed in a water bath at $54{ }^{\circ} \mathrm{C}$. The solutions were concentrated to $11.3,15.5,17.0,20.0,23.4$ and 25.0 ${ }^{\circ}$ Brix. All the obtained juices were filtered to remove
Table 1

Specifications of the $9.6^{\circ}$ Brix cashew juice

\begin{tabular}{lc}
\hline Moisture (\%) & 90.4 \\
Total sugars (\%) & 10.24 \\
Reducing sugars (\%) & 9.85 \\
pH & 3.88 \\
Fibers (\%) & 0.24 \\
\hline
\end{tabular}

suspended particles using a 50 mesh sieve with an opening width of $300 \mu \mathrm{m}$. The total soluble solids were measured by a bench refractometer (PZO Warszawa).

Each juice sample was placed in $50 \mathrm{ml}$ beakers. Error due to natural convection was avoided by adding $2 \%$ agar to the juice.

\subsection{Thermophysical properties}

The thermophysical properties were determined at 30 ${ }^{\circ} \mathrm{C}$, accurately controlled with a constant temperature circulation bath. Experiments were conducted in triplicate.

A Pycnometric method was used to determine the density of cashew apple. Pycnometers of $25 \mathrm{ml}$ capacity were used and they were calibrated with water. A water bath was used for controlling temperature.

A probe was used to measure simultaneously thermal conductivity and thermal diffusivity. The probe encloses a heater wire and a thermocouple junction contained in a hypodermical needles $(L=5 \mathrm{~cm}, D=0.2 \mathrm{~cm}$ for the thermal conductivity probe and $L=5 \mathrm{~cm}, D=0.1 \mathrm{~cm}$ for the thermal diffusivity probe). Construction of the line heat source probe is described by Choi and Okos (1983).

A constant electrical current of $3.6 \mathrm{~A}$ was applied to the heater wire. The system was computerized and a Scanlog data aquisition software recorded the thermocouple reading every $4 \mathrm{~s}$ for a total duration of $20 \mathrm{~min}$ (Fig. 1). A digital multimeter was used to check the voltage during data collection.

The thermal conductivity and the thermal diffusivity probes were positioned in the samples in such a way that

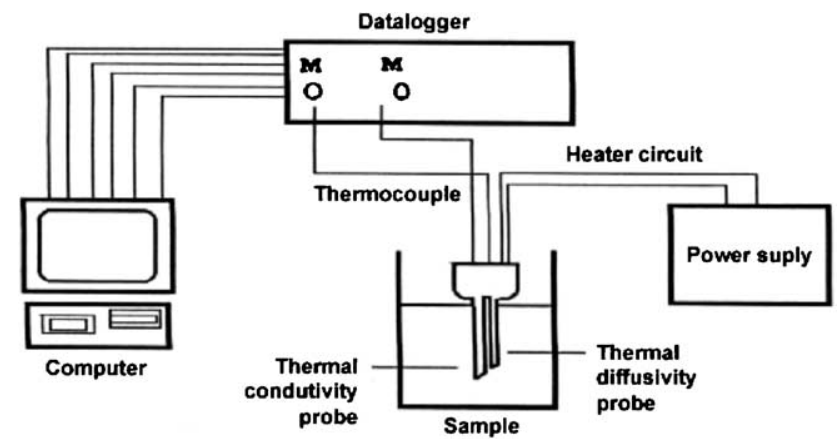

Fig. 1. Thermal conductivity and diffusivity measurement apparatus. 
the full length of the probes were covered. Thermal conductivity was calculated on the basis of Eq. (1). The heat input $Q$ in this equation was calculated from the resistance of the constantan heater and the electrical current, according to the equation $Q=I^{2} R$. The probe was tested by determining thermal conductivity and thermal diffusivity of water ( $2 \%$ agar).

A programmable Brookfield rheometer (LV DV-II+) was used to determine the viscosity and shear rate of juice. The sample was put in the concentric cylinder of the rheometer and heated in a water bath at $30^{\circ} \mathrm{C}$. The power law parameters were determined from the apparent viscosities measured at different shear rates.

\section{Results and discussion}

\subsection{Thermal conductivity and thermal diffusivity}

Experimental results of thermal conductivity $(k)$ and thermal diffusivity $(\alpha)$ at eight selected soluble solids levels ranging from 5.5 to $25^{\circ} \mathrm{Brix}$ at $30^{\circ} \mathrm{C}$ are shown in Figs. 2 and 3, respectively. There was a strong dependence of these properties on concentration and a noticeable decrease was observed as concentration increased. With an increase in water fraction of fruit juices, there is an increase in these thermal properties of fruit juices because compared with thermal conductivity and thermal diffusivity of the solids present in the juice, since water has a higher value of these properties.

Measurements of $k$ and $\alpha$ of cashew juice were not found in the literature. However, the obtained values fall into the range reported for other fruits and their products, like juices and pulps (Constenla, Lozano, \& Capriste, 1989; Jaramillo-Flores \& Hernandez-Sanchez, 2000; Singh, 1982; Zainal, Rahman, Ariff, Saari, \& Asbi, 2000).

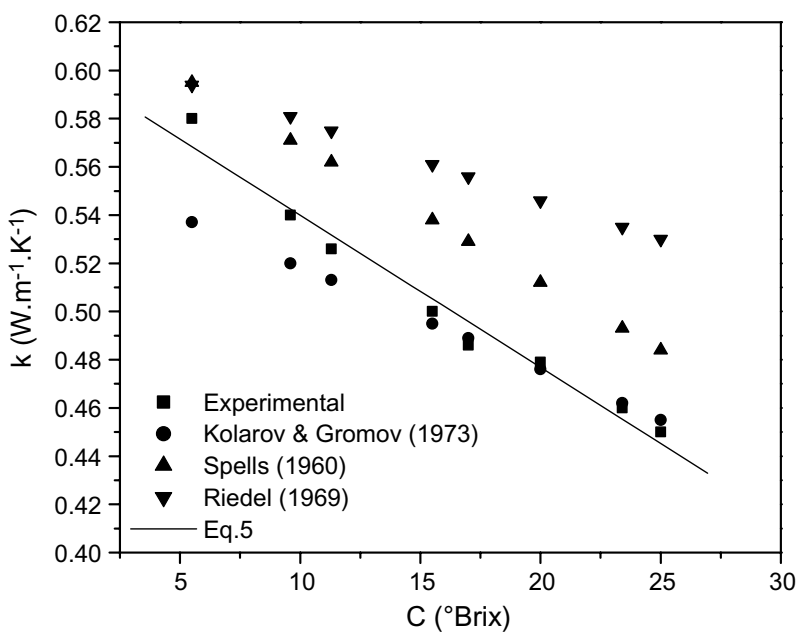

Fig. 2. Thermal conductivity of cashew juice at $30^{\circ} \mathrm{C}$.

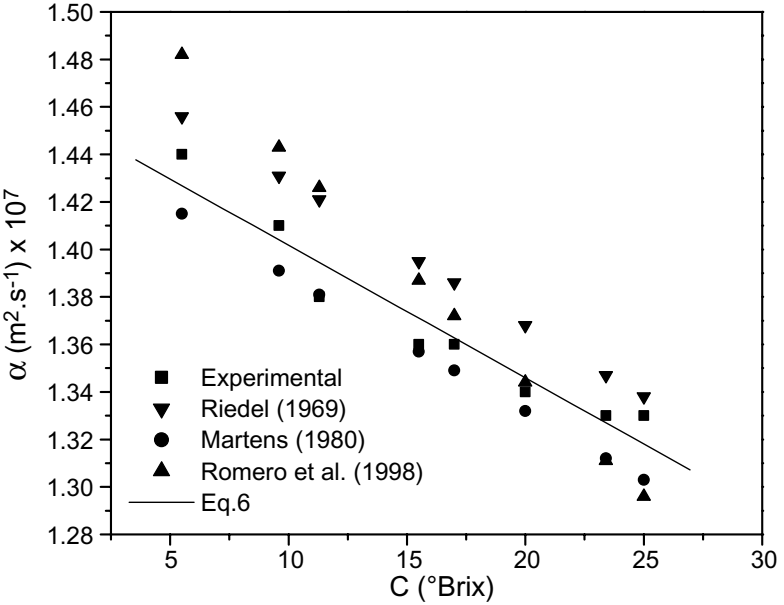

Fig. 3. Thermal diffusivity of cashew juice at $30{ }^{\circ} \mathrm{C}$.

Values of $k$ and $\alpha$ predicted by different models are shown in Figs. 2 and 3, respectively. It is seen that the proposed models are more accurate, with $R^{2}>0.93$ :

$k=0.5994-6.0527 \times 10^{-3} C \quad\left(R^{2}=0.974\right)$,

$\alpha=1.45751 \times 10^{-7}-0.00558 \times 10^{-7} C \quad\left(R^{2}=0.932\right)$,

where $C$ is the concentration ( $\left.{ }^{\circ} \mathrm{Brix}\right)$.

\subsection{Density}

The relationship between the density of cashew juice and soluble solids can be presented as a straight line (Fig. 4) and given as

$\rho=0.99562+0.00412 C \quad\left(R^{2}=0.996\right)$.

The density of cashew juice increased with increasing soluble solids concentration. This result is in agreement with depectined and clarified peach juice and orange

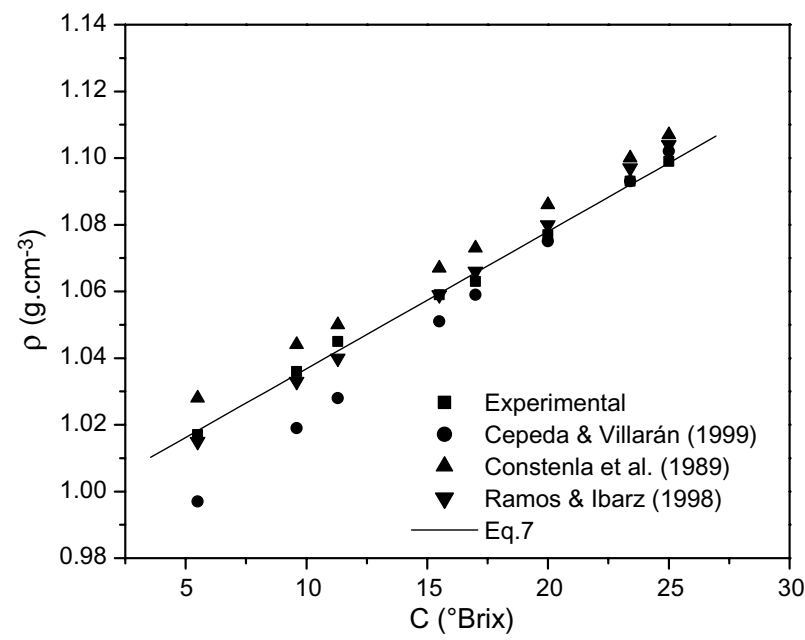

Fig. 4. Density of cashew apple at $30^{\circ} \mathrm{C}$. 
juice (Ramos \& Ibarz, 1998), cloudy and depectinised Malus floribunda juice (Cepeda \& Villarán, 1999), clarified apple juice (Constenla et al., 1989) and pink guava juice (Zainal et al., 2000).

Calculated data from the equation of Ramos and Ibarz (1998) are nearly coincident with the experimental data (Fig. 3), while the data predicted with the equation of Constenla et al. (1989) are different. Calculated data from the equation of Cepeda and Villarán (1999) are nearly coincident with experimental data at higher concentration values.

\subsection{Rheological measurements}

The experimental data showed a non-Newtonian behaviour for the cashew juice (Fig. 5), that retained its pseudoplastic characteristic, indicated by the value of the flow behaviour index $(n)$, being less than 1 (Table 2 ). Similar behaviour was found by Zainal et al. (2000) for pink guava juice and by Rao, Cooley, and Vitali (1994), who reported that the effect of concentration on viscosity of fruit juices at constant temperature could be

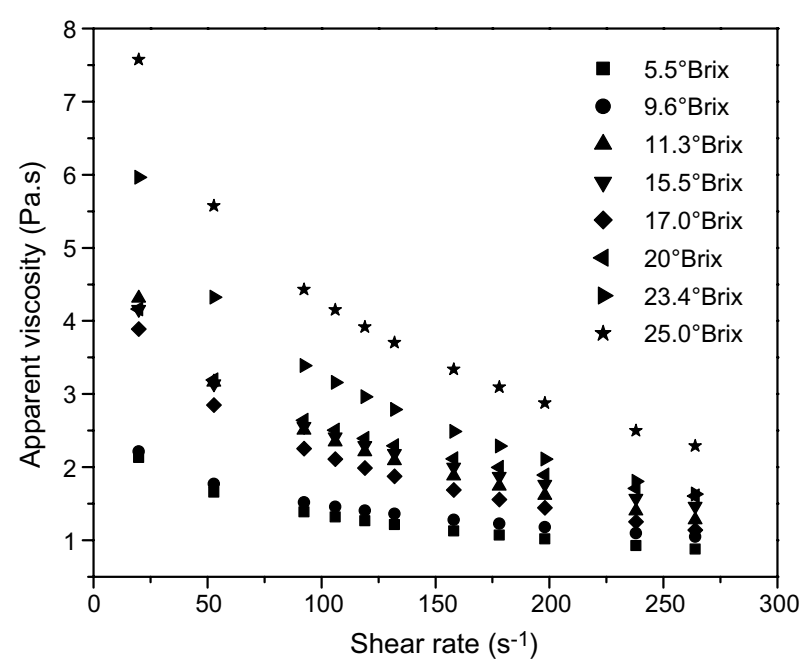

Fig. 5. Apparent viscosity of cashew juice versus shear rate.

Table 2

Values of consistency coefficient $(K)$ and flow behaviour index $(n)$ for cashew juice at different soluble solids concentration

\begin{tabular}{llll}
\hline $\mathrm{C}\left({ }^{\circ}\right.$ Brix $)$ & $K$ & $n$ & $R^{2}$ \\
\hline 5.5 & 0.0058 & 0.7337 & 0.985 \\
9.6 & 0.0039 & 0.8207 & 0.995 \\
11.3 & 0.0092 & 0.7256 & 0.988 \\
15.5 & 0.0076 & 0.7485 & 0.995 \\
17.0 & 0.0081 & 0.7230 & 0.996 \\
20.0 & 0.0113 & 0.6748 & 0.983 \\
23.4 & 0.0087 & 0.7979 & 0.995 \\
25.0 & 0.0121 & 0.7526 & 0.985 \\
\hline
\end{tabular}

represented by either an exponential-type or a powertype relationship.

Viscosity of cashew juice increased with soluble solids, as expected. Constenla et al. (1989) reported that, as in the case of density, the viscosity of a solution is a function of the intermolecular forces and water-solute interactions that restrict the molecular motion. These forces depend upon intermolecular spacings and the strength of the hydrogen bonds, and are affected by changes in both concentration and temperature. When more solutes such as sugars are dissolved in the solution, the viscosity increases because of the increase in hydrogen bonding with hydroxyl groups and the distortion in the velocity pattern of the liquid by hydrated molecules of the solute.

\section{Conclusions}

From this study, it was found that the physical properties were concentration dependent. Thermal conductivity and thermal diffusivity decreased with an increase in soluble solids concentration, while density and viscosity increased. The regression equations obtained in this study are capable of simulating the physical properties of cashew juice. The results of this work have direct application to fruit juice processes involving fluid flow and heat transfer.

\section{Acknowledgements}

The authors gratefully acknowledge the financial support of FAPESP (The State of São Paulo Research Foundation).

\section{References}

AbuDagga, Y., \& Kolbe, E. (1997). Thermophysical properties of surimi paste at cooking temperature. Journal of Food Engineering, $32,325-337$.

Bhumbla, V. K., Singh, A. K., \& Singh, Y. (1989). Prediction of thermal conductivity of fruit juices by a thermal resistance model. Journal of Food Science, 54(4), 1007-1012.

Blackwell, J. H. (1954). A transient-flow method for determination of thermal constants of insulating materials in bulk. Journal of Applied Physics, 25(2), 137-144.

Cepeda, E., \& Villarán, M. C. (1999). Density and viscosity of Malus floribunda juice as a function of concentration and temperature. Journal of Food Engineering, 41, 103-107.

Choi, Y., \& Okos, M. R. (1983). The thermal properties of tomato juice concentrate. Transactions of the ASAE, 26, 305-311.

Constenla, D. T., Lozano, J. E., \& Capriste, G. H. (1989). Thermophysical properties clarified apple juice as a function of concentration and temperature. Journal of Food Science, 54(3), 663-668.

da Silva, K. D., Collares, F. P., \& Finzer, J. R. D. (2000). A simple and rapid method for estimating the content of solids in industrialized cashew juice. Food Chemistry, 50, 247-250. 
de Moura, S. C. S. R., Germer, S. P. M., Jardim, D. C. P., \& Sadahira, M. S. (1998). Thermophysical properties of tropical fruit juices. Brazilian Journal of Food Technology, 1(1-2), 70-76.

Dickerson, R. W. (1968). Thermal properties of foods. In The freezing preservation of foods, Vol. 2 (4th ed.). Westport: AVI Publishing Co. Inc.

Jaramillo-Flores, M. E., \& Hernandez-Sanchez, H. (2000). Thermal diffusivity of soursop (Annona muricata L.) pulp. Journal of Food Engineering, 46, 139-143.

Nix, G. H., Lowery, G. W., Vachen, R. I., \& Tanger, G. E. (1967). Direct determination of thermal diffusivity and conductivity with a refined line-source technique. In G. G. Heller (Ed.), Progress in astronautics and aeronautics (pp. 113-116). New York: Academic Press.

Polley, S. I., Synder, O., \& Kotnour, P. (1980). A compilation of thermal properties of foods. Food Technology, 34(11), 7694.

Ramos, A. M., \& Ibarz, A. (1998). Density of juice and fruit puree as a function of soluble solids content and temperature. Journal of Food Engineering, 35, 57-63.

Rao, M. A., Cooley, H. J., \& Vitali, A. A. (1994). Flow properties of concentrated juices at low temperatures. Food Technology, 38, 113.
Riedel, L. (1949). Thermal conductivity measurement on sugar solutions, fruit juices and milk. Chemie Ingenieur-Technik, 21, 340.

Singh, R. P. (1982). Thermal diffusivity in food processing. Food Technology, 87-91.

Soares, J. B., \& Maia, G. A. (1970). Determinação colorimétrica de ácido ascórbico em alguns frutos regionais. Pesquisa Agropecuária no Nordeste (Recife), 2(2), 79.

Tocci, A. M., Flores, S. E., \& Mascheroni, R. H. (1997). Enthalpy, heat capacity and thermal conductivity of boneless mutton between -40 and $+40{ }^{\circ} \mathrm{C}$. Lebensmittel-Wissenschaft und Technologie, 30, 184-191.

Urbicain, M. J., \& Lozano, J. E. (1997). Thermal and rheological properties of foodstuffs. In K. J. Valentas, E. Robstein, \& R. P. Singh (Eds.), Handbook of food engineering practice (pp. 425-452). USA: CRC Press.

Van der Held, E. F. M., \& Van Drunen, F. G. (1949). A meted for measuring the thermal conductivity of liquids. Physica, 15, 865881.

Zainal, B. S., Rahman, R. A., Ariff, A. B., Saari, B. N., \& Asbi, B. A. (2000). Effects of temperature on the physical properties of pink guava juice at two different concentrations. Journal of Food Engineering, 43, 55-59. 